\title{
Breve historia de las Islas Chafarinas
}

Santiago Dominguez

Las Islas Chafarinas están situadas a tres grados, cincuenta y tres minutos de longitud Este, según el meridiano de San Fernando, y a 35 grados, doce minutos de latitud Norte. Distan tres millas de Cabo de Agua y unas 27 de Melilla.

Este archipiélago lo componen tres islas:

- Isla del Congreso: Es la mayor y la situada más al Oeste. Mide aproximadamente mil metros de Norte a Sur, siendo su máxima elevación de 137 metros. Es la más agreste del grupo, presentando en su cara Oeste grandes acantilados.

- Isla de Isabel II: Es la central y única habitada, su forma es casi circular. Su altura máxima ("La Conquista") es de 57 metros.

- Isla del Rey Francisco: Situada al Este de la anterior. Su forma es bastante irregular. En ella se encuentra el cementerio, hoy abandonado.

\section{HISTORIA}

Las Islas Chafarinas no han of recido grandes hechos históricos, aunque eso no signifique que no hayan tenido, y tengan, importancia.

Podemos delimitar dos etapas en la Historia de las Islas; la separación entre ellas sería la fecha del 6 de enero de 1848, día en que-se ejerció de manera efectiva el dominio español sobre ellas, aunque eran consideradas españolas desde mucho antes.

Antes de 1848:

Ya en trabajos del profesor Posac, se demuestra la existencia en las islas de la cultura neolítica, hecho que vienen a confirmar las recientes 
investigaciones del profesor De Mora Figueroa.

De otros trabajos se desprende la utilización de las islas como refugio para los navegantes desde tiempo inmemorial, así, figuran en el famoso itinerario del Emperador Antonino con el nombre de "Tres Insulae".

Los invasores árabes las llamaron "Yezirat Meluia" (Islas del Muluya) y también "Yezirat Quebdana". Por su parte, los habitantes de las costas próximas las denominaban "Shaffarin", nombre del que podría provenir su actual nombre; existe, no obstante, otra teor fa, defendida por Sangroniz, que le da como origen el de "Beni-Jafar", tribu que habitaba la cercana costa.

Los pol'́grafos árabes Abu Obeid El Bekri y el Xerif El Idrissi (siglo XII), mencionan la existencia de un archipiélago enfrente de la desembocadura del Muluya, frente a la villa de Yoroba; estas islas no pueden ser otras que las Chafarinas.

Las islas figuran en los más antiguos portulanos, como el realizado en el año 1318 por Pietro Visconti de Geres que las llama "Zafarin"; la Carta Catalana de 1375, realizada por Tastu y Buchon, las denomina Archipiélago de Quebdana. En 1436, Andrea Bianco las rotula "Zafarinni"; Juan de la Cosa, el famoso navegante española, las llama en 1493 "Farinas". Otros portulanos las denominan "Aljafarinas". Es a partir de 1602 cuando se generaliza el nombre de Chafarinas.

El aparecer en esta cantidad de portulanos nos confirma la importancia que poseían las islas como único puerto abrigado de la zona ante los vientos del primer cuadrante.

Pese a constituir tan excelente refugio, la permanencia estable en las islas era prácticamente imposible, debido a la falta total de agua potable. A pesar de esto, hay una cita en los avisos de Jerónimo Barrionuevo que dice que Génova habla enviado a la Isla Chafarina más de 2.500 hombres con vituallas, etc. Si esta ocupación fue cierta no nos han llegado testimonio de ella.

El primer reconocimiento formal que se hizo fue en 1733 por parte de don Juan José Navarro, Marqués de la Victoria, entonces Comandante del navío de guerra "San Fernando", el cual, encontrándose en Orán, recibió la orden expresa de reconocerlas. En la memoria que elevó al Rey llega a la conclusión de que eran "inmejorable fondeadero".

El levantamiento del primer plano topográfico del que tenemos noticias, es el realizad por el Capitán de Fragata, don Vicente Dolz, el cual en su informe llegó a las mismas conclusiones que el anterior.

Es durante el terrible asedio a que sometió a la ciudad de Melilla el Emperador de Marruecos Muely Abdallah en 1774-1775, cuando se reconoce el valor de las islas, y lo hacen precisamente dos de los más grande marinos que ha tenido la Armada española, don Vicente Hidalgo de Cisneros, Almirante de la flota de socorro y don Antonio Barceló, apodado 
"Terror de Corsarios", que mandaba la Escuadra Ligera de Jabeques. Es precisamente Barceló el que aconseja a los capitanes de la flota de socorro que tan pronto barruntasen tiempos duros "alzaran los ferros" poniendo proa a las Chafarinas. Por su parte, el Almirante Hidalgo de Cisneros en su memorandu al Rey le indica la necesidad de ocupar las islas por la gran utilidad que tuvieron.

Veamos el testimonio de uno de los más directos protagonistas de este asedio, el Capitán don Francisco de Miranda, el cual en su famoso diario dice:

"Día 23 (enero 1775):

Oi ha soplado un viento tan fuerte del suroeste, acompañado de alguna lluvia que obligó a nuestras embarcaciones a hacerse a la vela para las Chafarinas que es un puerto abrigado y distante de aqui nueve leguas-Es un Yslote o peñasco desierto, que forma un buen puerto en el que se refugian las embarcaciones que los malos tiempos arrojan sobre esta costa."

Los consejos que diera Barceló fueron repetidos más tarde por don Vicente Tofiño de San Miguel, que en 1786 levantó la carta marina del litoral mediterráneo ma rroquí.

A finales de 1775 vuelven a ser reconocidas por el Conde O'Reilly, para estudiar con detenimiento el aprovechamiento y defensa de las islas.

Son precisamente los trabajos de éste último los que despiertan la curiosidad del Rey de Francia, Luis XVI y algunos de sus ministros, que abrigaban propositos de efectuar algunas acciones militares en el Norte de Marruecos, propósitos que no se llevaron a cabo, ya que habiendo firmado hacía poco tiempo con el Sultán, un tratado, el haber ocupado cualquier punto del litoral hubiera supuesto romper dicho tratado, perdiendo Francia los beneficios come rciales que éste le reportaba.

Es en estos tiempos cuando las islas son prácticamente olvidadas por las autoridades españolas, no así por los habitantes de Melilla, que ya por esta época realizaban viajes a las islas a mariscar o a coger materiales de construcción.

En 1830, y a raíz de la intensa acción francesa en Argelia, es cuando el Gobernador de Melilla don Luis Cappa, advierte de las derivaciones que pudiera acarrear el perderlas.

Este año de 1830 ocurre un hecho, más bien una anécdota, que, por fortuna, no tuvo consecuencias: Una comisión de sabios y exploradores franceses, que recorria en viaje de estudios el litoral argelino-marroquí, se vio obligada a guarecerse en las islas ante un violento temporal. En este intervalo realizaron abundantes exploraciones cientificas. No teniendo ningún nombre en particular las islas, ellos les dieron los de Bonguiard, Buchland y Buck, nombres que no han perdurado.

Los repetidos triunfos de las armas francesas en Argelia, preocuparon al Gobierno, que transmitió ordenes al Capitán de navío. don Luis Her- 
nández Pinzón, entonces Comandante del navio de guerra "Isabel II" para que intensificara la vigilancia de las islas.

Ante el progresivo avance de los franceses, es nuevamente enviado el brigadier don Miguel Santillán con orden de planear la definitiva ocupación y artillado de las islas.

Por fin, se acuerda en el Consejo de Ministros del 26-6-1847 su ocupación e instalación de una fuerte guarnición. Fue encargado de realizar tal operación el entonces Capitán General de Granada, don Francisco Serrano Domínguez, haciendo el estudio completo de la ocupación el Gobernador de Melilla, don Demetrio María de Benito y su Estado Mayor.

A mediados de diciembre de 1847 se reúnen en Málaga los buques "Vulcano" (6 cañones), "Piles" (4 cañones), bergantín "Isabel II" y el mítico "Flecha" siendo sus comandantes don Nicolás Santaolalla, don Martín Ezpeleta, don Joaquín Urristieta y don Pedro del Castillo, respectivamente.

Las fuerzas de desembarco encargadas de la operación constaban de unos 550 hombres del primer batallón de Africa y del segundo de Navarra.

Embarcaron las tropas en Melilla en la tarde del 5 de enero en los correos "San José", "San Gabriel" y "Carmen", haciéndolo en el Piles el General Serrano y su séquito, acompañados por don Bartolomé de Fuentes, vicario de Melilla, encargado de bendecir las islas y bautizarlas como Congreso, Isabel II y Rey Francisco.

En la mañana del 6 de enero, y después de una corta pero penosa navegación a causa del mal tiempo, llegaron los expedicionarios a las islas, procediéndose al desembarco, efectuándolo de los primeros el General Serrano, que enarbolando la bandera gritó por tres veces la fórmula de posesión de las islas en nombre de España.

Inmediatamente dieron comienzo los trabajos de construcción de un desembarcadero y unos algibes. Mientras el vicario pasó en una falúa a las islas del Congreso y del Rey a bendecirlas, celebrándose después en la de Isabel II una misa, en la que se proclamó como Patrona de las islas a la Purísima Concepción.

Destacó en ese día la actuación de los desterrados que fueron llevados allí, así como la de los entonces pelotones de Africa, hoy Compañáa de Mar.

Quedó de Gobemador de las Islas el Coronel de Carabineros don Vicente Ilarduyen.

Al poco tiempo -aquí tampoco se ponen de acuerdo los historiadores, estimando algunos unas horas, y otros varios días- se presentó ante las islas una escuadra francesa al mando del Almirante Munchez, encargado de conquistarlas, no pudiendo hacerlo al estar ya ocupadas por España. 
A partir de enero 1848 :

Después de su ocupación, siguen en las islas los trabajos tendentes a su fortificación y habitabilidad. Posteriormente fueron declarados presidios sirviendo de auxiliar del de Melilla. En este presidio estuvieron detenidos, entre otros, bastantes insurgentes cubanos, entre ellos un hermano del insurrecto Maceo. Más tarde estuvieron presos varios marroquíes de los sublevados entre 1909-1927, entre éstos cabe destacar a Mohamed Assari, más popularmente conocido como "Moro Gato", o como Dris Ben Said, que durante su cautiverio se ocupo de traducir al árabe "El Quijote".

Existe una especie de leyenda que dice que Abdel-Krim estuvo en las islas detenido. Esto no es posible, ya que el citado se rindió a los franceses, quienes lo enviaron confinado a la Isla Reunión. Quien sí estuvo allí fue su Ministro de la Guerra, Mohamed Hamed Budra.

Otros confinados de importancia fueron los sublevados de Jaca del año 1930 , liberados al proclamarse la Repablica en 1931.

Volviendo atrás en el tiempo, se produce en 1885 el famoso incidente de las Carolinas, incidente que supuso la ocupación de dicho archipiélago por parte de Alemania. Es entonces cuando en todos los círculos patrios se clama por la fortificación de las islas, no fuera a ser que una potencia extranjera las ocupase para tener un puerto de aprovisionamiento a medio camino de Oriente.

De esta forma, se llevan a cabo las más ingentes obras en las islas, entre ellas la instalación de dos grandes cañones Trubia y Ordónez, 1869, uno en el baluarte de la Conquista, y el otro dominando el puerto, asi como otras piezas de mediano calibre. Como es natural en este país en cuanto se dejó de hablar del tema, se olvidaron todos los proyectos, quedando a medio hacer la may oria de las obras que se iniciaron.

El 18" de mayo de 1863, son declaradas junto a Ceuta y Melilla, puerto franco, convirtiéndose entonces en importante centro comercial, importancia que decayó con la conquista de Cabo de Agua.

Se pensó en varias ocasiones darle otra función a las islas, decidiéndose entonces el convertirlas en centro de cuarentena de los barcos que ven fan de América, pero la práctica demostró que las islas no cumplían las condiciones para ello, al no tener puerto ni alojamientos adecuados. Posteriormente, y a raíz de las campanias de 1921 , son convertidas en hospital de convalecientes, pudiendo acoger hasta 450 enfermos.

Esta misma función siguió desempeñando hasta 1956, fecha de la Independencia de Marruecos, siendo entonces reforzada su guarnición, cubierta hoy por el Grupo de Fuerzas Regulares Melilla, núm. 2.

Esta es sucintamente la historia de las Islas Chafarinas, un pequeño 
paraíso perdido, que no tiene hoy el valor estratégico que posefa cuando se ocuparon (su ocupación trajo como consecuencia el que Francia no pasara la línea del Muluya).

Sin embargo, posee hoy un valor quizá superior, el biológico, tema en el que no voy a incidir, ya que ya lo ha hecho el biólogo José Manuel Cabo en esta misma revista.

Ahora bien, a nivel informativo, voy a exponer los trabajos que se han realizado últimamente en las islas.

- Desde 1975, estudios de la colonia de Gaviota de Adouin (gaviota de pico rojo) por parte de los profesores de la Universidad de Madrid, Eduardo De Juana y Juan Valera, a cuenta de la World Wildlife Found. Hoy día sigue este trabajo la bióloga Patricia M. Bradley de la Universidad de Glasgow (Escocia), este ano ayudada por John Flagerty de La Bristol University.

- Desde 1983, estudio de la colonia de pardela cenicienta por parte de José Manuel Cabo y colaboradores de Melilla.

- Invierno 1983-84, estudio de aves invernantes en las islas por José Fernández Palacios, biólogo de la Universidad de Sevilla.

- 1983-84, reconocimiento arqueológico a cargo del Catedrático de Arqueología de la Universidad de Cádiz, doctor don Luis Mora Figueroa.

Este año siguen la mayorfa de estos trabajos, que esperamos dé resultados positivos. 


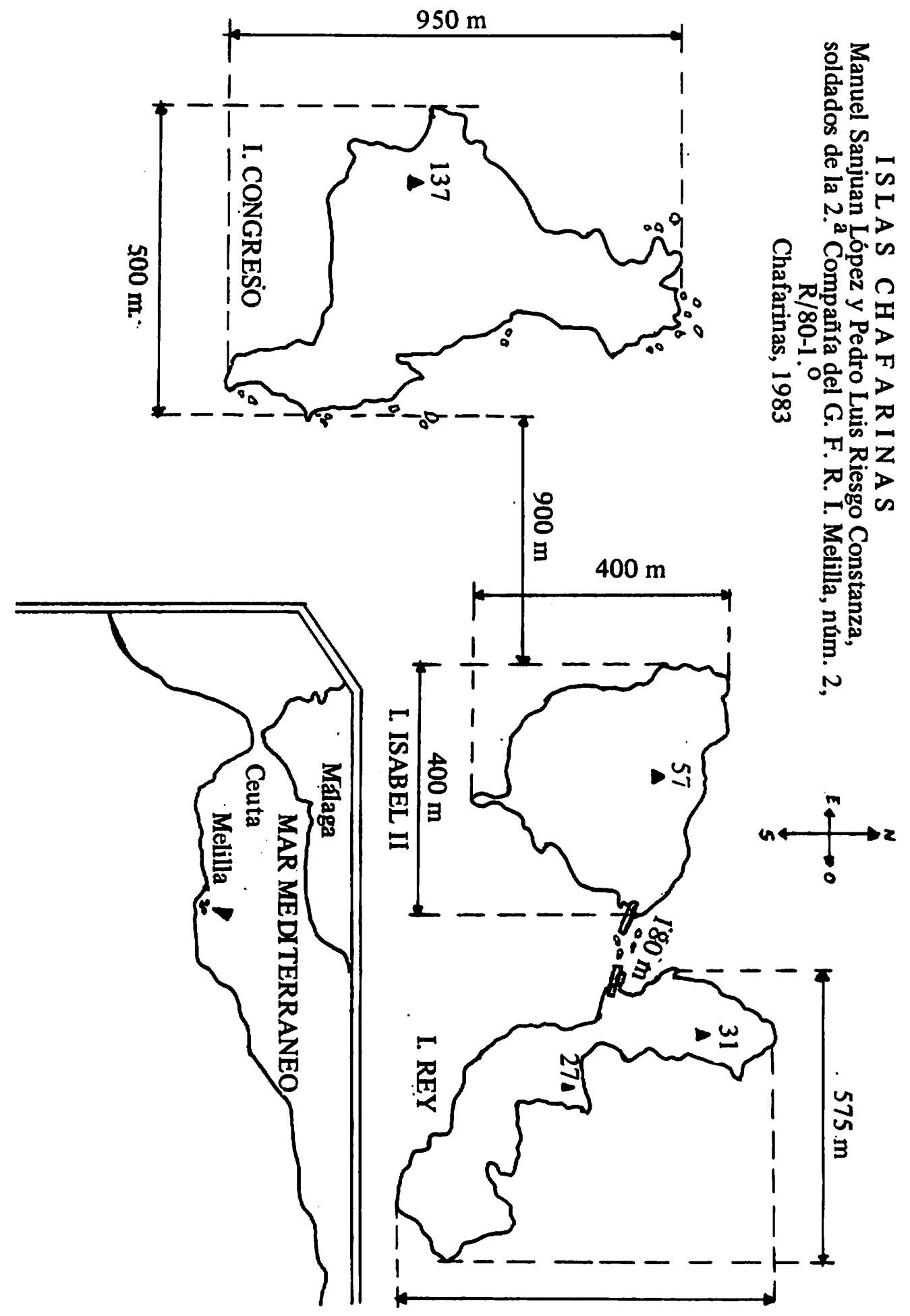



PROYECTO DE MEJORA DEL PUERTO DE CHAFARINAS EN LA COSTA DE AFRICA/Coronel
José Marfa Aparici
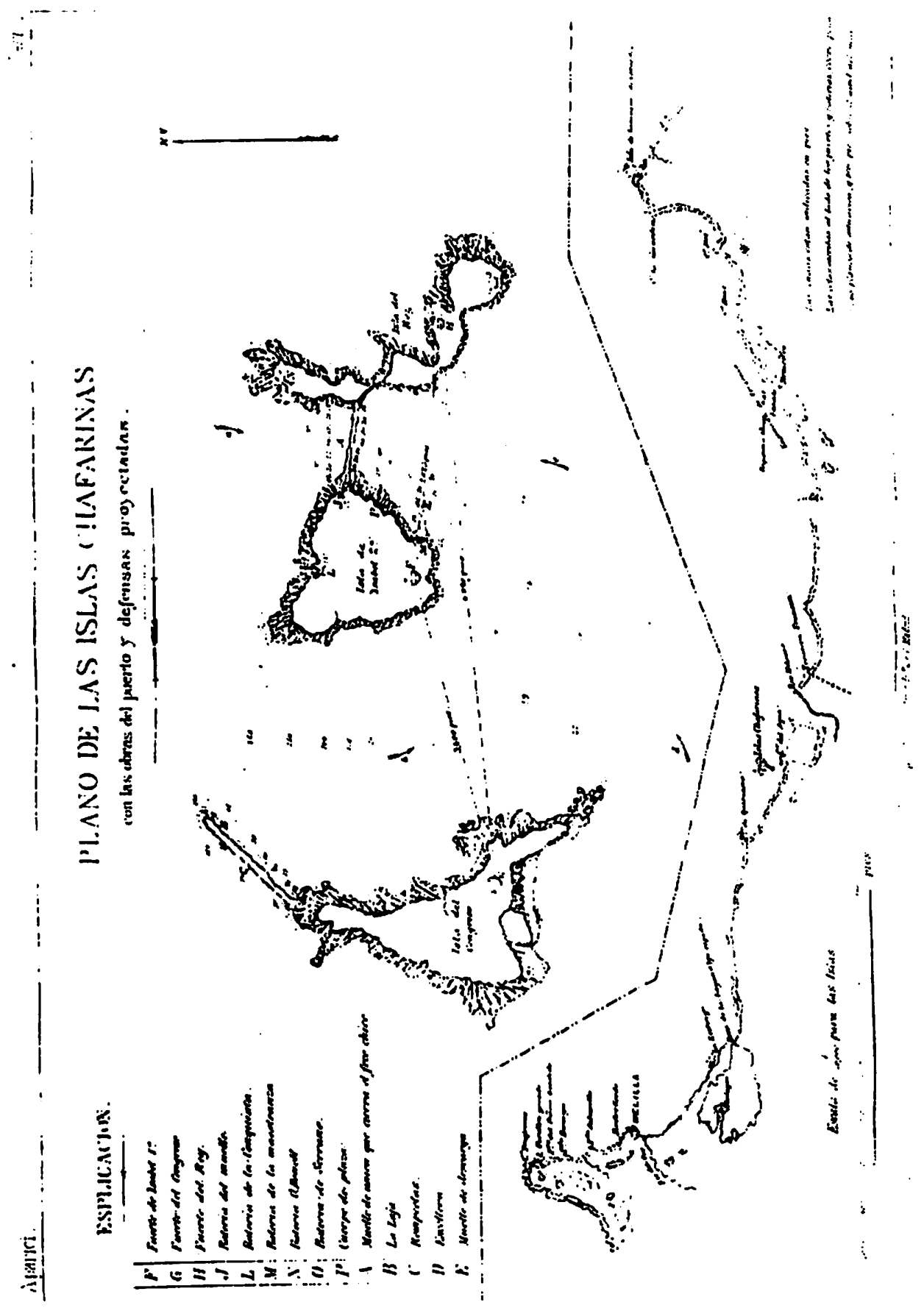


\section{BIBLIOGRAFIA Y FUENTES DOCUMENTALES}

ARQUES, Enrique: Las adelantadas de España, Madrid: Consejo Superior de Investigaciones Cientificas, 1966.

BELLO CRESPO, Marín: "Vélez, Alhucemas y Chafarinas", Rev. Ejército.

CALDERON, Salvador: "Las Chafarinas", Anales de la Sociedad Españala de Historia Natural. Serie $1 .{ }^{2}$, tomo 23, Madrid, 1984.

CARCAÑ̃, Francisco: "Las Plazas menores de Africa: Peñón de Vélez, Alhucemas y Chafarinas", Melilla: El Telegrama del Rif, 1920.

CARTOTECA Histórica del Servicio Geográfica del Ejército.

ESTEBAN-INFANTES y MARTIN, Emilio: Expediciones españolas del siglo $X I X$, Madrid: Instituto de Cultura Hispánica, 1949.

FERNANDEZ DE CASTRO Y PEDRERA, Rafael: Rev. Africa. "Primer centenario de la ocupación del Archipiélago de Chafarinas", 1948.

MIR BERLANGA, Francisco: Floresta de pequefias historias, Melilla: Ayun tamiento de Melilla, 1983.

MIRANDA, Francisco de: El sitio de Melilla. Presentado por Fernández de Castro y Pedrera, Tánger, 1939.

PEZZI, Rafael: Los presidios menores de Africa y la influencia espafiola en el Rif, Madrid, 1983. POPULAR, El. Diversos artículos.

POSAC, Carlos: "Estudio de la industria lítica hallada en la Isla del Congreso, Chafarinas", Tamuda, Tetuán, 1956.

SANGRONIZ, José Antonio de: "Las Islas Chafarinas", Boletin de la Real Sociedad Geogrdfica", tomo LXIV, Madrid, 1923.

TELEGRAMA DEL RIF, El. Diversos artículos.

VARELA, Juan Manuel. "Islas Chafarinas: paraje privilegiado con futuro incierto", Quercus, núm. 1, Madrid, 1981.

Varios autores: "La posesión de las Islas Chafarinas", Boletín de la Real Academia de la Historia. tomo LXXIX, cuaderno V, Madrid, noviembre de 1921. 